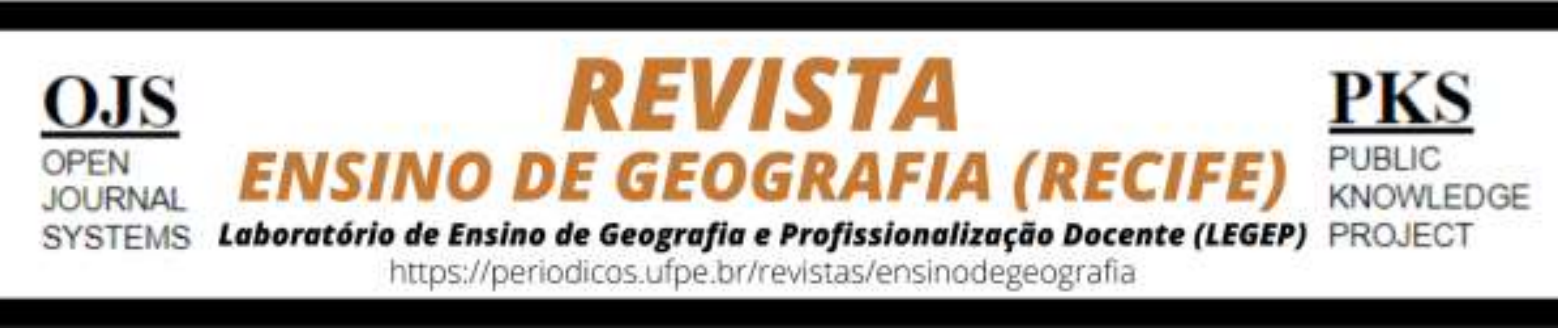

\title{
A PROVA NA AVALIAÇÃO DA APRENDIZAGEM ESCOLAR: ELEMENTOS CARACTERIZADORES DO INSTRUMENTO DE VERIFICAÇÃO DE APRENDIZAGEM
}

\author{
Elaine Cristina Medeiros Pereira ${ }^{1}$, Francisca Samara Kizia Bezerra do Nascimento², José \\ do Carmo Filho ${ }^{3}$, Lucas Gabriel Silva ${ }^{4}$, Maria das Lágrimas Leite Minervino ${ }^{5}$, Tânia \\ Cristina Meira Garcia ${ }^{6}$
}

\begin{abstract}
1 Mestranda do Programa de pós-graduação em Geografia - GEOPROF - CERES. E-mail: elaineufrn@gmail.com - ORCID Id: http://orcid.org/0000-0001-8329-9113

2 Universidade Federal do Rio Grande do Norte. E-mail: samara_kisia@hotmail.com - ORCID Id: http://orcid.org/0000-0002-5715-919X

3 Graduação em Geografia pela Universidade Federal do Rio Grande do Norte. E-mail: josefilho1963@hotmail.com - ORCID Id: http://orcid.org/0000-0001-7240-8310

${ }^{4}$ Professor e Especialização em Educação Ambiental e Geografia do Semiárido (Campus Natal Zona Leste). E-mail: professorlucasgabriel@gmail.com - ORCID Id: http://orcid.org/0000-0003-4848-4027

5 Professora do Governo do Estado da Paraíba. E-mail: profmariaminervino@gmail.com - ORCID Id: http://orcid.org/0000-0003-4183-3220

${ }^{6}$ Professora da Universidade Federal do Rio Grande do Norte. E-mail: tania_cristina2005@yahoo.com.br ORCID Id: http://orcid.org/0000-0002-5488-3684
\end{abstract}

Artigo recebido em 04/01/2020 e aceito em 07/04/2020

\begin{abstract}
RESUMO
Este estudo discute a avaliação da aprendizagem escolar na área do ensino de Geografia, a partir da identificação dos elementos caracterizadores do instrumento de verificação de aprendizagem - PROVA. O objetivo é analisar a PROVA a partir de dois aspectos: a) Quanto ao conteúdo de ensino abordado, na relação com o planejamento do professor, identificando os assuntos e temas, a fim de verificar a correlação e a qualidade técnica da indicação de conhecimentos, habilidades e atitudes a serem validadas. b) Quanto às características didático-pedagógicas (design): tipo de questões; distribuição de questões; formulação das perguntas; chave-de-correção e forma de divulgação dos resultados. A amostra do tipo aleatória é composta de instrumentos de avaliação na modalidade PROVA, aplicados em escolas públicas e privadas, tendo como critérios de inclusão que o instrumento aborde conteúdo do ensino de Geografia; aplicado em turma do Ensino Fundamental; elaborado pelo professor responsável pelo ensino do conteúdo. O método de análise se fundamenta na estatística descritiva simples (FEIJOO, 2010). Quanto aos resultados identificamos que a maior parte dos indicadores de fragilidade dos instrumentos PROVA estão associados aos aspectos técnicos, com ênfase, naqueles relacionados a priorização de tipos de questões e o domínio de conhecimentos e habilidades.
\end{abstract}

Palavras-chave: Ensino; Geografia; Avaliação; Prova. 


\title{
THE EVIDENCE IN ASSESSING SCHOOL LEARNING: CHARACTERIZING ELEMENTS OF THE LEARNING VERIFICATION INSTRUMENT
}

\begin{abstract}
This study discusses the evaluation of school learning in the area of geography teaching, from the identification of the elements that characterize the learning verification instrument - PROVA. The objective is to analyze the PROVA from two aspects: a) Regarding the teaching content approached, in relation to the teacher's planning, identifying the subjects and themes, in order to verify the correlation and the technical quality of the indication of knowledge, skills and attitudes to validate. b) The didactic-pedagogical characteristics (design): type of questions; distribution of questions; formulation of questions; correction-key and form of disclosure of the results. The sample of random type is composed of evaluation instruments in the PROVA modality, applied in public and private schools, having as inclusion criteria that the instrument addresses the geography teaching content; applied in the elementary school class; prepared by the teacher responsible for teaching the content. The method of analysis is based on simple descriptive statistics (FEIJOO, 2010). As for the results we identified that most of the indicators of fragility of the PROVA instruments are associated with the technical aspects, with emphasis on those related to the prioritization of types of questions and the domain of knowledge and skills.
\end{abstract}

Key words: Teaching; Geography; Evaluation; Proof.

\section{INTRODUÇÃO}

A avaliação de aprendizagem escolar representa fecundo tema de discussão e debate (PERRENOUD, 1999; GRÉGOIRE, 2000; HOFFMAN, 2001; FILIZOLA, 2009; RUSSEL, 2015). Estudada e analisada a partir de diferentes abordagens (política, didática e pedagógica) ainda apresenta um amplo espectro de especulação científica que tendencialmente se amplia no momento atual, em que a educação brasileira enfrenta o desafio de adotar uma formação com forte acento no desenvolvimento de competências (BNCC, 2017). A avaliação da aprendizagem, por sua complexidade e nuances, assume entre educadores de todos os matizes um dos aspectos mais controversos, ao se discutir a educação sistematizada. As divergências quanto ao seu papel, objetivo e função dentro do processo de aprendizagem têm gerado confusão e incompreensão, sendo a avaliação, muitas vezes, colocada na condição de vilã. A falta de uma atenção mais acurada dos cursos de formação de licenciados, no que refere aos estudos sobre a avaliação e, no que respeita a sua função e procedimentos, tem muitas vezes contribuído para insegurança e improvisos. Ao confundir procedimentos (objetivos e métodos) com tipo de instrumentos, ou ferramentas de coletas de informação sobre rendimento escolar (prova, teste, questionário, relatório) professores e especialistas em educação têm encontrado dificuldade em compreender a relevância e caráter indispensável que a avaliação tem para o acompanhamento do progresso do aluno. 
A Prova, tipo de instrumento composto por questões que são pontuadas para se chegar a um resultado em termos de nota, tem sido vista, via de regra, como pouco eficaz, e muitas vezes desaconselhável quando refere à verificação da aprendizagem escolar. Essa posição tem como suporte a falsa tese de que esta, caracteriza uma educação baseada na memorização, atributo que tem como construção na história da educação o tempo em que a prática do professor em sala de aula, assim como os métodos de ensino e a tecnologia educacional, se restringiam aos limites da sala de aula e ao ensino diretivo. $\mathrm{O}$ avanço alcançado pela pesquisa no campo do ensino e da aprendizagem escolar, resultante da contribuição da psicologia (cognitiva e da aprendizagem) e da neurociência, tem trazido à cena a evidência de que não é o tipo de instrumento que define a qualidade do processo de avaliação, mas sim o método e as características didático-pedagógicas presentes na elaboração do instrumento. Inspirado nesses debates é que este estudo problematiza a avaliação escolar na perspectiva da análise do instrumento Prova, a partir da questão problema: Como tem sido elaborado o instrumento Prova, para avaliação da aprendizagem em Geografia do ponto de vista didático-pedagógico e técnico (design)?

Desse modo, buscando responder a questão a investigação teve como objetivo geral analisar a Prova, instrumento de avaliação da aprendizagem em Geografia, do ponto de vista didático-pedagógico e técnico (design), identificando indicadores de fragilidade quanto à elaboração de critérios de verificação da aprendizagem do conteúdo (conhecimentos e habilidades) e quanto aos aspectos técnicos (design) de organização do instrumento. Para isso, adotou os seguintes objetivos específicos:

1. Elaborar background teórico estruturador do aporte que apontará os indicadores, descritores e categorias os quais serão utilizados para a análise descritivo-interpretativa dos instrumentos.

2. Identificar e descrever os elementos didático-pedagógico e técnico (design) dos instrumentos de avaliação de aprendizagem em Geografia (Prova), considerando:

a) O conteúdo de ensino abordado, na relação com o planejamento do professor, identificando os assuntos e temas, a fim de verificar a correlação e, a qualidade técnica da indicação de conhecimentos, habilidades e atitudes a serem validadas; 
b) As características didático-pedagógicas (design) quanto ao tipo de questões; distribuição de questões; formulação das perguntas; chave-de-correção e forma de divulgação dos resultados.

3. Apontar procedimentos técnicos (didáticos) que visem à correção das fragilidades identificadas nos instrumentos analisados.

O método de análise dos dados coletados se fundamentou na estatística descritiva simples (FEIJOO, 2010). Para composição do aporte teórico o método privilegiado foi a revisão narrativa para, através dela, buscar destaque para as discussões sobre a aprendizagem escolar a partir da identificação das bases neurológicas da aprendizagem e as condições humanas e ambientais que lhe são peculiares (LENT, 2010); COSENZA (2013). Para a avaliação escolar na perspectiva da identificação de paradigmas e modelos elegeu-se Coll et al. (2000, 2004), Perrenoud (1999) e Sacristán e Gómez (1998).

\section{O LUGAR DA PROVA NOS DISCURSOS SOBRE AVALIAÇÃO DA APRENDIZAGEM ESCOLAR}

Apesar do significativo avanço das pesquisas, a avaliação escolar ainda é vista como tema de ampla complexidade, diante das funções impostas fora e dentro da escola. Nessa perspectiva destacam-se as funções sociais e as funções didáticas e pedagógicas. A primeira focada nos processos normativos e de certificação, na direção do exercício para viver em sociedade e ingressar no mercado de trabalho. E a A segunda referente à dimensão exemplar da prática docente estreitada ao processo diagnóstico (COLL; MARTÍN; ONRUBIA, 2004).

Em meio às ponderações sobre a avaliação em comento e, para além destas, outras podem ser agregadas no intuito de enriquecer as pesquisas referentes a temática. Uma destas é no que refere aos instrumentos para coleta de dados utilizados para verificação de aprendizagem a partir do instrumento Prova.

Como já sabido os instrumentos de coletas de dados, para a avaliação, auxiliam no processo diagnóstico da aprendizagem e subsidiam a tomada de decisão do professor ao palnejamento de novas atividades, visto que, os instrumentos de coleta de dados para a 
avaliação são extremamente úteis para o desenvolvimento da avaliação a serviço da aprendizagem do educando na escola (LUCKESI, 2018).

Dada a importância dos instrumentos de coleta de dados para a prática avaliativa, a sua construção deve atentar para que o carater diagnóstico da aprendizagem seja o mais fiel possível. Para Luckesi (2018) as características fundamentais de um instrumento de coleta de dados para a avaliação referem a sistematicidade ou abrangência dos conteúdos; a linguagem compreensível; a compatibilidade entre o ensinado e o apreendido e pôr fim a precisão. Tais características são indispensáveis para que os instrumentos de avaliação estejam em sintonia com aquilo que está sendo desenvolvido ou como tem sido desenvolvido nas aulas (FILIZOLA, 2009) e no planejamento da ação docente. É necessário atentar, também, para o tipo de abordagem de avaliação adotada pelo profesor de modo que testes, cadernos, textos, desenhos, anotações do professor sobre o aluno se tornem instrumentos que funcionem como o termômetro, radiografia, ou prontuário que indique que caminho o profesor e o aluno devem seguir. (HOFFMAN, 2014).

A forma de abordagem, interpretação e uso dos instrumentos de coleta de dados para o processo avaliativo reflete na concepção teórica e metodológica referente à aprendizagem na qual o professor se assenta. Também é revelada que função a avaliação denota, seja a social de certificação e seletividade, ou a didático-pedagógica com os aspectos diagnósticos dos conhecimentos construídos.

A prova, como instrumento de coleta de informações, poderá estar a serviço de ambas as funções, como expressa Perrenoud (1999), uma vez que este instrumento assegura valores precisos no que tange a confiabilidade socialmente referendada.

Nesse cenário, o que irá definir a função que a prova terá no processo de avaliação é justamente a sua elaboração, análise e juízo empregado pelo profesor no contexto da ação docente. Para Moretto (2010, p. 119) "se tivemos de elaborar provas, que sejam bem-feitas, atingindo seu real objetivo, que é verificar se houve a aprendizagem significativa de conteúdos relevantes." Isso nos faz asseverar que a escolha por este instrumento precisa estar fundamentado na perspectiva diagnóstica e formativa da aprendizagem.

É preciso salientar que a ideia de avaliação formativa tem na ação docente o seu funcionamento, levando o professor a observar mais metodicamente e qualitativamente os alunos, a compreender melhor seus funcionamentos no processo de aquisição do 
conhecimento, de modo a ajustar e regular de maneira mais sistemática e individualizada suas intervenções pedagógicas e as situações didáticas que propõe, tudo isso na expectativa de otimizar as aprendizagens (SACRISTÁN; GÓMEZ, 1998).

Como sabido, as provas prevalecem como escolha no sistema escolar de avaliação, por serem consideradas pelos profesores como instrumentos potenciais de identificação das competências construídas pelos estudantes. Embora muito criticado por um grupo específico de estudiosos e investigadores da avaliação escolar, que denunciam a face examinativa, classificatória e pontual, este instrumento e sua prática são defendidos pelos demais, defensores da avaliação externa a escola, adeptos dos instrumentos padronizados de avaliação, como instrumento apto a apresentar resultados mais precisos sobre o domínio das competências escolares.

Vilas Boas (2008) faz um convite para ao uso da prova, intentando chamar a atenção para que através da sua aplicação com rigor didático-pedagógico sejam superadas as características classificatórias que desabonam seu uso, e desmitifique os malefícios amplamente acentuados. (Re)pensá-la com base em princípios formativos parece ser uma alternativa, uma vez que quando bem elaborada, possibilita analisar a apropriação dos mais diversos saberes pelos educandos (MORAES, 2008).

A medida que se centra sua construção nos princípios formativos da aprendizagem, possibilita-se ressignificar o seu uso para avaliação da aprendizagem, e consequentemente dotá-la do ponto de vista didático-pedagógico e técnico, das aprendizagens conceituais, procedimentais e atitudinais.

\section{METODOLOGIA}

Amostra do tipo aleatória composta de instrumentos de avaliação na modalidade PROVA, aplicados em escolas públicas e privadas, situadas em diferentes municípios dos estados do Rio Grande do Norte (RN), Paraíba (PB) e Ceará (CE) no Nordeste Brasileiro, sede das atividades profissionais dos pesquisadores. Colobaradores-professores autores dos instumentos prova, escolhidos aleatoriamente, adotado como critério de inclusão que o instrumento abordasse o conteúdo do ensino de Geografia; aplicado em turma do Ensino Fundamental, elaborado pelo professor responsável pelo ensino do conteúdo e que a atividade docente estivesse pautada em planejamento didático elaborado. Os colaboradores 
da pesquisa foram 19 (dezenove) professores vinculados as redes de ensino dos Municípios de São João do Sabugi, Jucurutu e Caicó, (RN), São Bento e Patos (PB) e Aracati (CE), com tempo de experiência no ensino que variam entre 19 (dezenove) e 05 (cinco) anos de atuação. Amostra composta de 01 (um) instrumento de avaliação aplicado por cada um dos 19 (dezenove) professores participantes, no primeiro bimestre letivo, referente, ao conteúdo de Geografia, em turma de alunos do $6^{\circ}$ ano do Ensino Fundamental. Foram excluídos os instrumentos que compõem exames padronizados ou integrem procedimentos de avaliação externa.

O método de análise se fundamentou na estatística descritiva simples (FEIJOO, 2010). Os professores que autorizaram o exame dos instrumentos Prova, o fizeram mediante assinatura de Termo de Consentimento Livre Esclarecido.

Para composição do aporte teórico o método privilegiado foi a revisão da narrativa a partir de referências indicadas pela Coordenadora da Pesquisa.

Inicialmente as informações da pesquisa foram coletadas através de entrevista oral com o professor colaborador, em seguida, por meio da análise dos seus planejamentos didáticos e instrumentos Prova. Foram disponibilizadas 19 (dezenove) provas, os dados coletados dos instrumentos foram tabulados, analisados e interpretados buscando atender aos objetivos da pesquisa.

\section{RESULTADOS}

Nesta seção apresentamos a análise-descritiva dos elementos didático-pedagógico e técnico (design) dos instrumentos de avaliação de aprendizagem em Geografia (Prova). A discussão dos dados analisa, primeiramente, o nível de formação dos docentes colaboradores da pesquisa, o conteúdo de ensino abordado, na relação com o planejamento do professor, os assuntos e temas, a fim de verificar a correlação e, a qualidade técnica da indicação de conhecimentos, habilidades e atitudes a serem validadas. Em seguida, apresenta as características didático-pedagógicas (design) das provas quanto aos tipos de questões; distribuição de questões; formulação das perguntas; chave-de-correção e forma de divulgação dos resultados aos alunos. 


\section{Perfil dos colaboradores}

Em se tratando do grau de formação dos profissionais da amostragem da pesquisa (Tabela 01), pode-se constatar que 63,16\% destes possuem graduação em Geografia com pós-gradução em diferentes áreas (História e Cultura Africana e Afrobrasileira; Educação Ambiental e Geografia do Semi-árido; Geografia e meio ambiente; e Novas Tecnologias em Educação). Verifica-se que 21,05\% dos que têm formação na área geográfica não possuem pós-graduação. Os dados apontam que os colaboradores têm nível de formação compatível com o que disciplina a Lei de Diretrizes e Bases da Educação Nacional (LDB, 1996), que define:

Art. 62. A formação de docentes para atuar na educação básica far-se-á em nível superior, em curso de licenciatura, de graduação plena, em universidades e institutos superiores de educação, admitida, como formação mínima para o exercício do magistério na educação infantil e nas quatro primeiras séries do ensino fundamental, a oferecida em nível médio na modalidade Normal. (BRASIL, 1996, p. 20).

Tabela 01 - Escolaridade dos docentes

\begin{tabular}{|c|c|c|}
\hline ESCOLARIDADE DOS DOCENTES & QUANTIDADE & $\%$ \\
\hline Graduação em Geografia sem pós-graduação & 04 & $21,05 \%$ \\
\hline Graduação em Geografia com pós-graduação (Variadas) & 12 & $63,16 \%$ \\
\hline $\begin{array}{l}\text { Outra graduação (Licenciatura em História) sem pós- } \\
\text { graduação }\end{array}$ & 01 & $5,26 \%$ \\
\hline $\begin{array}{l}\text { Outra graduação (Licenciatura em História) com pós- } \\
\text { graduação }\end{array}$ & 02 & $10,53 \%$ \\
\hline TOTAL & 19 & $100,00 \%$ \\
\hline
\end{tabular}

Fonte: Elaborado pelos autores com base nos dados coletados no mês de junho do ano de 2019.

Aspecto que merece destaque refere a presença de $15,79 \%$ de colaboradores com formação em área diferente da de Geografia, aspecto que pode impactar no tratamento didático dado por estes profissionais ao ensino dos conteúdos dessa área de conhecimento.

\section{Conteúdos escolares de geografia nos documentos e nas provas}

Em relação aos conhecimentos geográficos, os documentos oficiais brasileiros Parâmetros Curriculares para o Ensino Fundamental, Ensino de Geografia (1997, Vl. 05), as Diretrizes Curriculares Nacionais (2013) e, mais recentemente, a Base Nacional Comum 
Curricular (2017), direcionam os conteúdos e assuntos partindo de problemáticas da Geografia. Para cada tema são sugeridos tópicos de estudos a serem explorados pelos professores. O documento da BNCC indica que os tópicos de estudos objetivam "sinalizar percursos de aprendizagem e desenvolvimento dos estudantes ao longo da Educação Básica" (BNCC, 2017, p. 7). Em relação a Geografia, a BNCC afirma que a sua grande contribuição aos alunos da Educação Básica é:

[...] desenvolver o pensamento espacial, estimulando o raciocínio geográfico para representar e interpretar o mundo em permanente transformação e relacionando componentes da sociedade e da natureza. Para tanto, é necessário assegurar a apropriação de conceitos para o domínio do conhecimento fatual (com destaque para os acontecimentos que podem ser observados e localizados no tempo e no espaço) e para o exercício da cidadania (BNCC, 2017, p. 358).

Com aporte nas diretrizes e considerando que os conteúdos são essenciais para o domínio das competências, habilidades e atitudes para o densenvolvimento do pensamento espacial, buscou-se identificar os conteúdos de ensino avaliados nos instrumentos Prova, em consonância com o que estava previsto no planjemanto de ensino dos colaboradores.

A Tabela 02 mostra que a maioria dos professores $(84,21 \%)$ abordou os conteúdos pautados no eixo temático "Conceitos geográficos (paisagem, espaço e lugar), Orientação e localização".

Tabela 02 - Conteúdo de Ensino

\begin{tabular}{l|c|c|}
\multicolumn{1}{c|}{ CONTEÚDO DE ENSINO } & ENTREVISTADOS & $\%$ \\
\hline $\begin{array}{l}\text { Conceitos geográficos (paisagem, espaço e } \\
\text { lugar), Orientação e localização }\end{array}$ & 16 & $84,21 \%$ \\
\hline $\begin{array}{l}\text { Estrutura geológica da terra } \\
\text { Dinâmica e estrutura da terra }\end{array}$ & 1 & $5,26 \%$ \\
\hline Clima e tempo atmosférico & 1 & $5,26 \%$ \\
\hline TOTAL & 1 & $5,26 \%$ \\
\hline
\end{tabular}

Fonte: Elaborado pelos autores com base nos dados coletados no mês de junho do ano de 2019.

Os conteúdos de ensino apresentados na Tabela 02 estão apresentados em consonância com as diretrizes apontadas nos documentos norteadores da educação básica, em ênfase, na BNCC (2017), que no que refere ao Ensino Fundamental, afirma que a linguagem cartográfica é importante instrumento de compreensão do mundo. Além disso, a 
BNCC (2017) enfatiza que o aluno deve adquirir o entendimento do mundo em suas diferentes espacialidades e temporalidades, dessa forma, o eixo que trata do "Espaço Geográfico e as dinâmicas socioambientais”, reforçam o entendimento do raciocínio geográfico com base nos conceitos de natureza, paisagem, espaço, região, território e lugar que dialogam com tempo, ambiente, poder, cultura e relações econômicas e sociais, aspectos e tópicos tratados pelos colaboradores.

\section{Relação entre os conteúdos geográficos e os assuntos explorados nos instrumentos $\underline{\text { Prova }}$}

A Tabela 03 aponta a relação existente entre os conteúdos geográficos e os assuntos explorados nos instrumentos Prova. Constatou-se que $84,21 \%$ dos profesores abordaram assuntos em consonância com o eixo temático "Conceitos geográficos (paisagem, espaço e lugar), Orientação e localização", como já apontado, havendo, portanto, consonância com o que está proposto na BNCC (2017) e, que, geralmente, é ensinado e avaliado no primeiro bimestre do ano letivo no nível de ensino universo do estudo. Evidenciando também que apesar destes professores estarem distribuidos em 04 (quatro) estados da região Nordeste, se orientam através das proposições da BNCC (2017), como demonstrado na Tabela 03.

Tabela 03 - Temas e assuntos abordados nas Provas

\begin{tabular}{|c|c|c|c|}
\hline CONTEÚDOS & ASSUNTO DAS PROVAS & $\begin{array}{l}\text { ENTREVIS } \\
\text { TADOS }\end{array}$ & $\%$ \\
\hline \multirow{3}{*}{$\begin{array}{l}\text { Conceitos geográficos } \\
\text { (paisagem, espaço e lugar), } \\
\text { Orientação e localização }\end{array}$} & $\begin{array}{c}\text { Formação das paisagens, } \\
\text { transformações das paisagens e } \\
\text { tipos de paisagens }\end{array}$ & 4 & $21,05 \%$ \\
\hline & $\begin{array}{l}\text { Conceito de paisagens, lugar e } \\
\text { espaço geográfico. Tipologia da } \\
\text { paisagem, sistema solar, } \\
\text { solstício e equinócio, } \\
\text { coordenadas geográficas, } \\
\text { paralelos e meridianos. }\end{array}$ & 6 & $31,58 \%$ \\
\hline & $\begin{array}{l}\text { Conceito de espaço geográfico, } \\
\text { paisagem e tipos de paisagem; } \\
\text { Orientação no espaço }\end{array}$ & 6 & $31,58 \%$ \\
\hline \multirow[t]{2}{*}{$\begin{array}{l}\text { Estrutura geológica da terra, } \\
\text { Dinâmica e estrutura da terra }\end{array}$} & $\begin{array}{l}\text { Camadas da terra, placas } \\
\text { tectônicas, cordilheiras, vulcões } \\
\text { e terremotos. }\end{array}$ & 1 & $5,26 \%$ \\
\hline & $\begin{array}{l}\text { Formas de relevo, massas de ar, } \\
\text { precipitações, fatores climáticos, }\end{array}$ & 1 & $5,26 \%$ \\
\hline
\end{tabular}




\begin{tabular}{|c|c|c|c|}
\hline \multirow[t]{2}{*}{ Clima e tempo atmosférico } & tempo atmosférico e clima & & \\
\hline & $\begin{array}{c}\text { Clima e tempo e tipos de } \\
\text { paisagens }\end{array}$ & 1 & $5,26 \%$ \\
\hline TOTAL & & 19 & $100,00 \%$ \\
\hline
\end{tabular}

Os conteúdos "Estrutura e dinâmica geológica da terra, Clima e tempo", conforme aponta a Tabela 03, podem ter sido planejados dentro das condições de flexibilidade e abertura consideradas pela BNCC (2017) e pelos PCNs (1997) a fim de priorizar necessidades locais ou da própria proposta curricular da escola. Podendo não significar dissonância entre o ensino e a aprendizagem.

No que se refere as competências, habilidades e atitudes apreciadas nos instrumentos, os dados apresentados na Tabela 04 apontam que a maioria dos professores avaliou o domínio dos conhecimentos e habilidades dos alunos. É relevante destacar ainda que $26,32 \%$ dos entrevistados consideraram nesse processo avaliativo apenas o domínio de conhecimento.

Tabela 04 - Competências, habilidades e atitudes

\section{COMPETÊNCIAS, HABILIDADES E ATITUDES}

\section{ENTREVISTADOS}

Apenas domínio do conhecimento

Conhecimentos, habilidade e atitudes

Apenas domínio do conhecimento e habilidade com clareza

Apenas domínio do conhecimento e habilidade por dedução

Apenas domínio do conhecimento/conhecimentos, habilidades e atitudes/ habilidades apenas por dedução Apenas domínio do conhecimento e atitudes com clareza TOTAL DE ENTREVISTADOS

\begin{tabular}{|l|c|}
\hline 05 & $26,32 \%$ \\
\hline 02 & $10,53 \%$ \\
\hline 07 & $36,84 \%$ \\
\hline 03 & $15,79 \%$ \\
\hline 01 & $5,26 \%$ \\
\hline 01 & $5,26 \%$ \\
\hline 19 & $100,00 \%$ \\
\hline
\end{tabular}

Fonte: Elaborado pelos autores com base nos dados coletados no mês de junho do ano de 2019.

$\%$

Coll et al. (2004) apontam que a melhor estratégia para assegurar a aprendizagem do educando e diminuir as fragilidades quanto à elaboração de critérios de avaliação, é fazer uma seleção adequada dos conteúdos, visto que essa ação implicará diretamente no domínio das competências de elaboração do conhecimento.

Em suma, o desenvolvimento das competências está atrelado a procedimentos de características cognitivas, psicomotores ou sócio-afetivas. Se bem estimuladas, tais 
aspectos juntamente com o conhecimento teórico ou as experiências cotidianas, proporcionam ao educando, um saber fazer. Trata-se de um saber que construímos ao longo de nossas vivências, onde o seu desempenho consiste no fazer concreto, garantido pelas competências. Já as habilidades correspondem ao saber fazer e não apenas o fazer.

Por este motivo Coll et al. (2004) afirma que não se deve avaliar uma única esfera do processo de ensino e aprendizagem, mas sim, tudo o que engloba o saber, o saber fazer e o querer fazer do aluno, só assim é possível constituir o real significado para tais competências.

\section{Características didático-pedagógicas (design) das provas}

Para avaliar as esferas globais do saber, o professor deve ter uma preocupação especial com os tipos de questões que irá selecionar para avaliar os alunos, não devendo priorizar apenas um estilo, mas oferecer diferentes tipologias que mobilizem diferentes operações cognitivas, operativas e atitudinais. Por este motivo, buscamos identificar nos instrumentos de avaliação de aprendizagem em Geografia (Prova) a quantidade e os tipos de questões utilizadas para avaliar o conhecimento dos alunos. A partir dos dados coletados, conforme são apresentados na Tabela 05, evidencia-se que as questões são apresentadas em tipologias variadas, predominando as objetivas (única escolha) e as dissertativas.

Tabela 05 - Quantidade e tipos de questões

\begin{tabular}{|l|c|c|}
\hline \multicolumn{1}{c|}{ QUESTÕES } & QUANTIDADE & PORCENTAGEM \\
\hline Múltipla escolha & 13 & $8 \%$ \\
\hline Única escolha & 52 & $31,90 \%$ \\
\hline Verdadeiro ou falso & 10 & $6,13 \%$ \\
\hline Resposta curta & 21 & $12,88 \%$ \\
\hline Associação de resposta & 08 & $4,91 \%$ \\
\hline Lacunas & 10 & $6,13 \%$ \\
\hline Dissertativa & 45 & $27,61 \%$ \\
\hline Outra & 04 & $2,45 \%$ \\
\hline TOTAL & 163 & $100,00 \%$
\end{tabular}

Fonte: Elaborado pelos autores com base nos dados coletados no mês de junho do ano de 2019. 
Podemos identificar que das 163 (cento e sessenta três) questões presentes nos instrumentos Provas, 97 (noventa e sete) referem-se ao domínio de conhecimentos, 57 (cinquenta e sete) a habilidades e 09 (nove) a atitudes.

A organização das questões na prova pode se diversificar de acordo com o planejamento e o propósito de execução. Depresbiteris e Tavares (2008) enfatizam que para evitar a exaustão dos alunos durante a realização de uma prova, o professor deve mesclar os tipos de questão. Nessa perspectiva, Luckesi (2011) defende que para diminuir as fragilidades quanto aos aspectos técnicos (design) de organização do instrumento prova, é necessário que esta incorpore em sua estrutura, questões específicas, sem que haja ambivalências; devendo incluir um único conteúdo em cada questão; prezar por uma linguagem clara e, considerar os esforços de estudar e aprender de cada estudante.

Quando bem elaborada, a prova permite ao professor averiguar o nível de apropriação dos saberes por parte do aluno. Dessa maneira, dependendo dos objetivos didáticos propostos para o instrumento, os conhecimentos conceituais, procedimentais e atitudinais podem ser enriquecidos (MORAES, 2008).

Na Gráfico 1 são apresentados os percentuais da distribuição das questões por tipo (objetivas e subjetivas). Ao analisar a distribuição das questões nos 19 (dezenove) instrumentos pesquisados, foi observado que 52,63\% dos professores distribuem as questões da prova de forma aleatória, ou seja, elas não são organizadas ou agrupadas por tipo de questão. Enquanto que $(47,37 \%)$ dos instrumentos analisados apresentaram os itens/questões distribuídos por tipo.

Figura 1 - Distribuição das questões no instrumento - prova

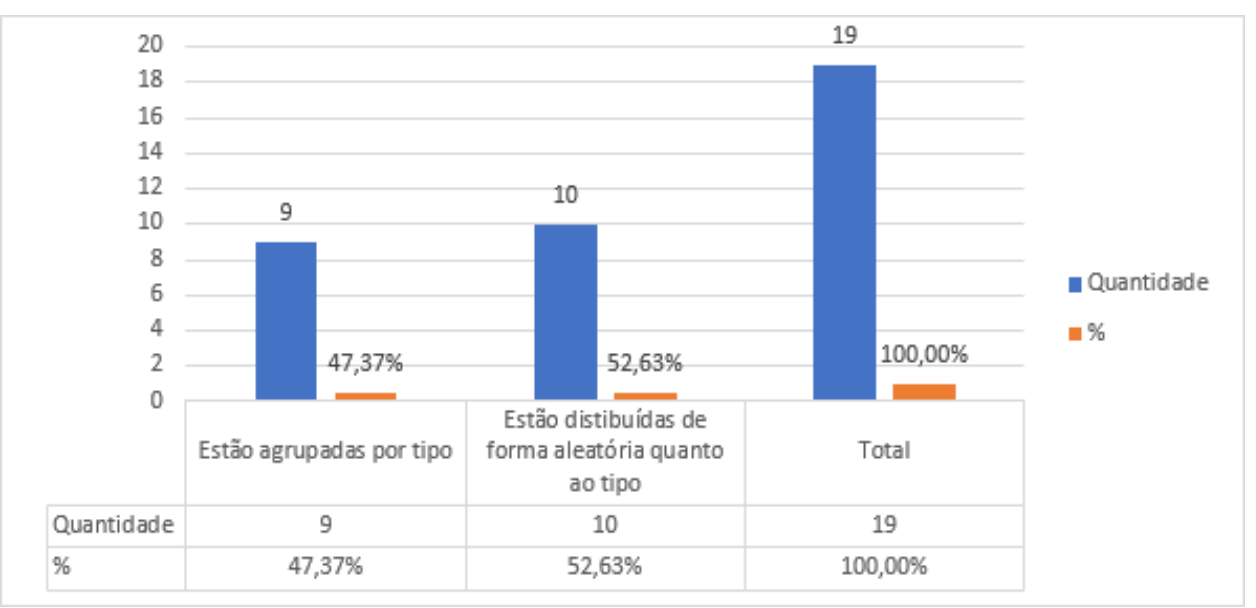

Fonte: Elaborado pelos autores com base nos dados coletados no mês de junho do ano de 2019. 
Outro aspecto que demonstra a organização do instrumento (prova) no formulário (papel) é o espaçamento entre as questões, ou seja, como elas estão distribuídas no corpo da lauda. Em relação a este aspecto, buscamos analisar se as questões das provas analisadas estavam separadas com espaço suficiente a ponto de facilitar a leitura. A partir da análise das provas, conforme está apresentado no Gráfico 2, identificamos que a maioria dos professores $(89,47 \%)$ elaborou seus instrumentos com espaços suficientes entre as questões, oferecendo espaçamento adequado para rascunhos, realização de cálculos e sistematização das respostas discursivas.

Gráfico 2 - Distribuição das questões no formulário (papel), quanto ao espaço para leitura

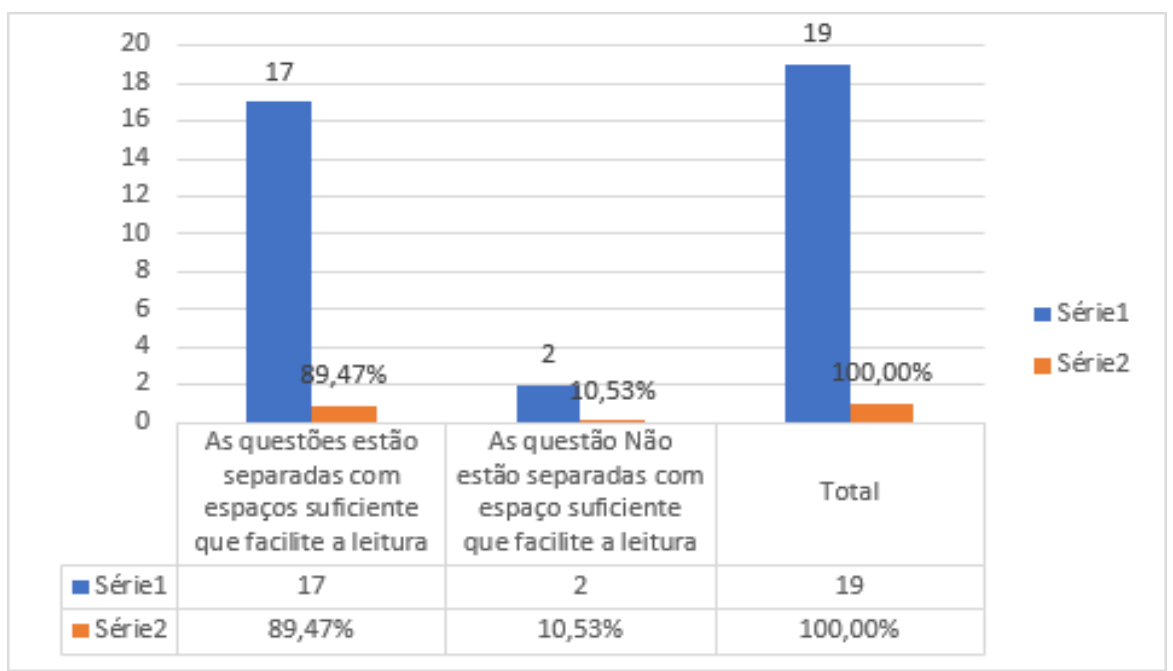

Fonte: Elaborado pelos autores com base nos dados coletados no mês de junho do ano de 2019.

A literatura científica da área da avaliação da aprendizagem demonstra expressiva preocupação em relação à forma como os professores estão elaborando os instrumentos avaliativos, uma vez que formulações inadequadas podem causar fracasso e, consequentemente, reprovação do aluno, comprometendo sua motivação durante o processo de aprendizagem escolar. Segundo o Manual de elaboração e revisão de questões publicado pela empresa Kroton (2017), muitos professores não sabem como elaborar uma prova que atenda aos procedimentos técnicos de espaçamento entre questões ou até aqueles referentes à estruturação do texto base, enunciados e alternativas. Muitas vezes não conseguem ter clareza sobre o que se quer avaliar e como transformar a avaliação num 
processo que não seja meramente de cobranças de conteúdos, memorização e sem significado para o aluno.

Segundo Moretto (2002) o professor deve atentar-se para algumas características essenciais de uma prova bem elaborada, visando à linha de construção do conhecimento que contemplem a contextualização e a parametrização.

Outra característica de importância nos instrumentos prova, e que julgamos ser objeto de preocupação do professor, é a linguagem e a redação das perguntas dos instrumentos de avaliação, uma vez que estas devem permitir ao educando a apropriação de informações, proporcionando e incitando a compreensão do que se quer como resposta, seja esta objetiva ou subjetiva. Considerando que toda pergunta busca uma resposta, devese observar se as palavras de comando e os enunciados das questões apresentam clareza e precisão, pois as respostas são dependentes da estrutura da pergunta. Nesse sentido é de suma importância que o docente saiba trabalhar com uma linguagem acessível aos alunos, de maneira a propiciar-lhe condições de avaliação que constatem o desenvolvimento de habilidades e atitudes.

A partir dos dados apresentados na Tabela 06, podemos observar que as provas apresentaram fragilidades no vocabulário, uma vez que apenas $31,25 \%$ possuíam termos acessíveis ao nível de escolaridade dos alunos, bem como não deixavam claro o que aluno deveria fazer para sistematizar a resposta.

Tabela 06 - Formulação (redação das perguntas) dos instrumentos

\section{REDAÇÃO E LINGUAGEM DAS PERGUNTAS}

Perguntas são curtas e diretas

As perguntas utilizam vocabulário adequado ao nível de ensino

As perguntas indicam claramente qual a ação que se espera que o aluno apresente ao formular a resposta

As perguntas expressam claramente qual o domínio de conhecimento está sendo avaliado

TOTAL

Fonte: Elaborado pelos autores com base nos dados coletados no mês de junho do ano de 2019.

\section{TOTAL}

11

15

14

08

48
$\%$

$22,92 \%$

$31,25 \%$

$29,17 \%$

$16,67 \%$

$100,00 \%$

O Manual de elaboração e revisão de questões da empresa Kroton (2017, p. 09), ao discutir sobre a linguagem e a redação de perguntas em provas, afirma que as questões 
devem ser elaboradas respeitando 11 (onze) critérios: objetividade, concisão, ordem direta, adequação, simplicidade, correção da linguagem, clareza, precisão, impessoalidade, adjetivos e advérbios, e regionalismo (devendo-se evitar terminologias regionais muito específicas, incompreensíveis para outras regiões).

Nesse sentido, as provas analisadas apresentaram fragilidades em relação a alguns dos critérios apresentados anteriormente, uma vez que demonstraram inadequações quanto ao uso da língua portuguesa, vocabulário inacessível ao nível de escolaridade dos alunos e falta de clareza quanto ao que se pretendia comunicar. Também podemos citar que algumas questões apresentavam ambiguidade, remetendo para mais de uma resposta.

Moretto (2002, p. 99) ao discutir sobre o processo de avaliação da aprendizagem escolar e, mais precisamente, dos instrumentos prova, afirma que estas devem ser elaboradas com concisão, pois "se a pergunta não for clara e precisa, ela permite muitas respostas, todas "corretas", embora diferentes das "esperadas" por quem perguntou. (...) uma resposta numa prova deve ser dada em função do contexto do ensino, isto é, de acordo com que o professor apresentou na aula". Nesse sentido, as questões devem ser formuladas buscando atender aos objetivos de aprendizagem planejados para o aluno. Se as indagações expostas na prova não forem bem estruturadas, poderá propiciar ao aluno dificuldades de interpretação e resolução e, consequentemente, os objetivos didáticos não serão alcançados.

Além da linguagem e redação das perguntas, outro fator importante que merece análise-descritiva dos pesquisadores refere-se aos critérios de correção das provas adotados pelos professores. Conforme apresentado no Gráfico 3, observamos que a maior parte dos docentes elaborou chave-de-correção. 
Gráfico 3 - Professores que utilizam chave de correção

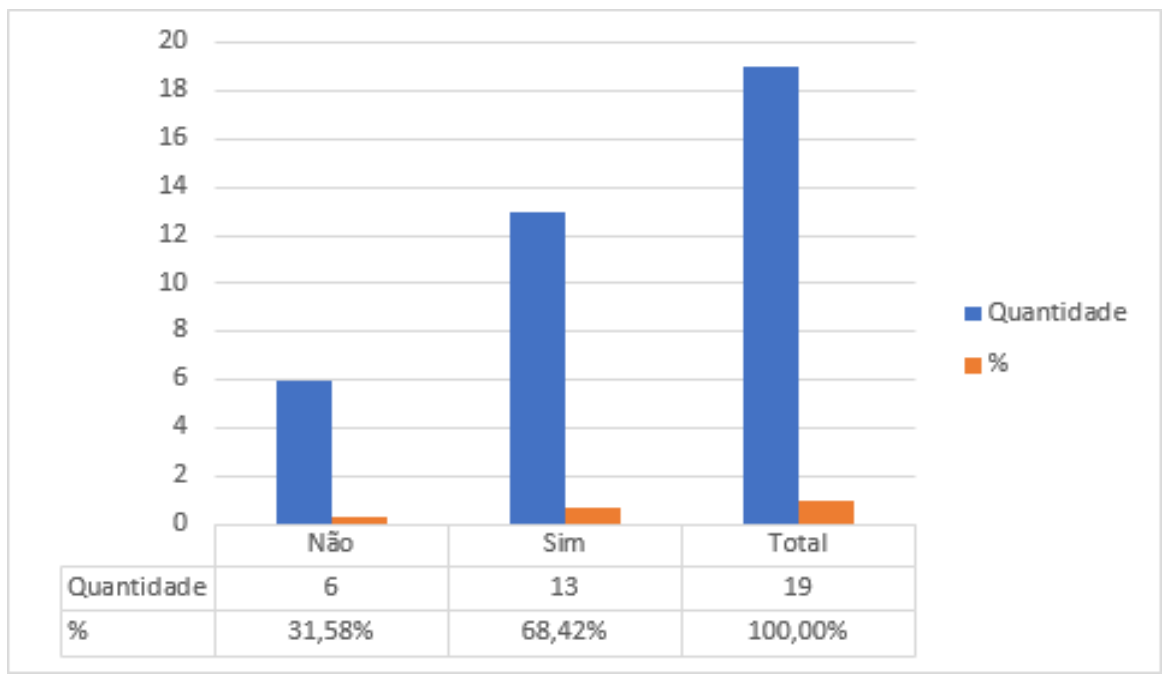

Fonte: Elaborado pelos autores com base nos dados coletados no mês de junho do ano de 2019 .

Os dados demonstram que os professores de Geografia envolvidos na pesquisa têm conhecimentos sobre a chave-de-correção, mas apenas $68,42 \%$ elaborou critérios de avaliação dos instrumentos. De acordo com Moretto (2010), a chave-de-correção consiste na definição de critérios e informações importantes a serem apresentadas no corpo das respostas dadas pelos alunos.

Nesse sentido, buscamos saber dos professores quais os critérios utilizados para sistematizar a chave-de-correção das provas, conforme o Gráfico 4, 63,16\% dos docentes elaborou a chave-de-correção de acordo com os objetivos didáticos estabelecidos no planejamento.

Gráfico 4 - Chave de correção em consonância com os objetivos didáticos

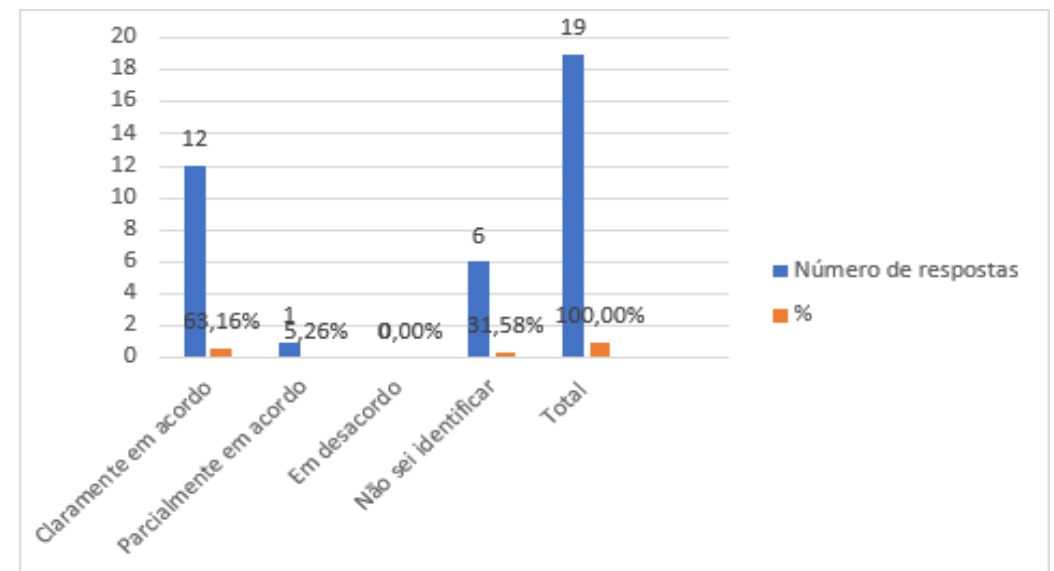

Fonte: Elaborado pelos autores com base nos dados coletados no mês de junho do ano de 2019. 
Durante a pesquisa com os professores, buscamos também identificar se estes disponibilizaram o gabarito da prova para os alunos. As respostas foram dadas com base nas seguintes opções de afirmações ou negações: "Sim, logo após a aplicação da prova"; "Sim, no dia de entrega do resultado"; "Não há entrega de gabarito ao aluno". Conforme os dados do Gráfico 5, a maioria dos professores $(57,89 \%)$ entregou o gabarito da prova ao aluno, 36,84\% concedeu no dia de entrega do resultado, e somente $21,05 \%$ forneceram o gabarito logo após a avaliação. Um percentual significativo dos professores entrevistados $(42,11 \%)$ não faz a entrega do gabarito aos alunos.

Gráfico 05 - Disponibilização do gabarito ao aluno

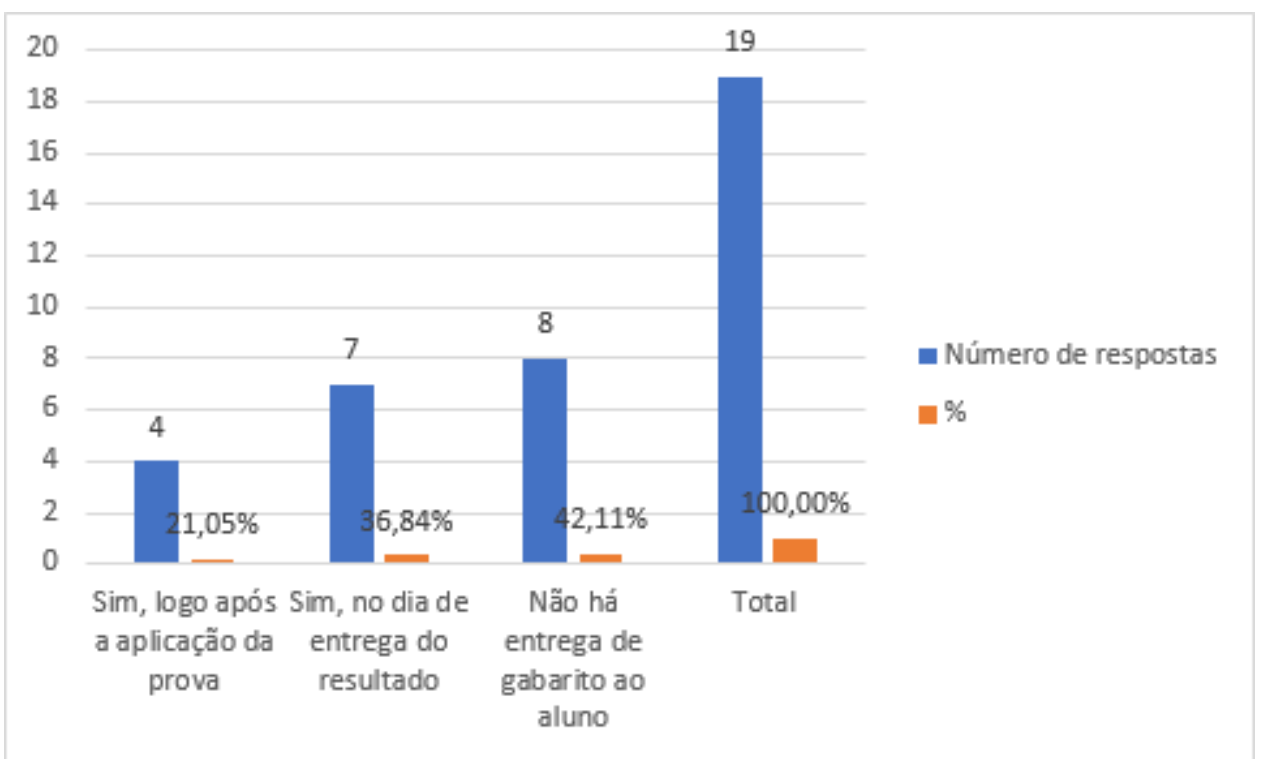

Fonte: Elaborado pelos autores com base nos dados coletados no mês de junho do ano de 2019.

Apesar de nem todos os professores entregarem o gabarito da prova aos alunos, os dados da pesquisa revelam que todos eles comunicam o resultado da avaliação e fazem correção dos erros em sala de aula. Segundo Hoffmann (1993), as dúvidas e os erros dos alunos consistem em um aspecto de grande valia para o desenvolvimento da ação educacional. Tal ato possibilitará a análise e investigação de como o discente irá reagir em relação ao processo de construção de suas verdades.

Em relação a isto, Luckesi (2006, p.179) afirma que "é preciso estar atento ao processo de correção e devolução dos instrumentos de avaliação da aprendizagem escolar aos educandos". Por isso, cabe ao professor não somente devolver as avaliações aos 
alunos, mas principalmente fazer a correção do instrumento corrigido. Considerar o "erro" do aluno é parte importante do seu aprendizado e do crescimento, além de mecanismo para o professor realizar sua autoavaliação, no sentido de verificar suas práticas como possibilidades de alcançar os objetivos propostos.

\section{CONSIDERAÇÕES FINAIS}

Esse estudo analisou a Prova, enquano instrumento de avaliação da aprendizagem em Geografia, do ponto de vista didático-pedagógico e técnico, identificando indicadores de fragilidade quanto à elaboração de critérios de avaliação do conteúdo e quanto aos aspectos técnicos de organização do instrumento. Em relação a isto, podemos asseverar, a partir dos dados coletados, que todos os professores que estavam lecionando a disciplina de Geografia possuíam nível de Ensino Superior, mas nem todos tinham formação específica na área geográfica.

Identificou-se que a maior parte dos indicadores de fragilidade dos instrumentos Prova estavam associados aos aspectos técnicos, em ênfase, aqueles relacionados a priorização de tipos de questões e ao domínio de conhecimentos e habilidades. Além disso, quase metade dos instrumentos apresentavam questões organizadas por tipo, não havendo mescla entre estilos de perguntas.

Outro aspecto a ser pontuado, diz respeito a linguagem das questões, que em sua maioria apresentava vocabulário inadequado para o público do $6^{\circ}$ ano do Ensino Fundamental, tendo perguntas que não expressavam claramente qual o domínio de conhecimento e a ação que estava sendo avaliada.

Podemos afirmar que os professores que elaboraram chave-de-correção para os instrumentos avaliativos, fizeram em consonância com os objetivos didáticos do planejamento. E-Apesar da maioria dos docentes não entregar o gabarito da prova aos alunos, todos eles comunicam o resultado da avaliação e fazem correção dos erros em sala de aula.

Seria pretensioso achar que a análise-descritiva dos instrumentos Prova se resume a este trabalho, uma vez que estaríamos negando a grande quantidade de informações que ainda há para ser investigado. Embora estejamos convencidos de que os aspectos didáticopedagógico e técnico dos instrumentos de avaliação sejam características basilares para 
quem se propõe avaliar, do ponto de vista estritamente lógico, pode-se ainda ponderar que outras particularidades dos intrumentos devam ser destacadas como determinantes para que o professor de Geografia consiga fazer o acompanhamento do progresso do aluno, por exemplo: que abordagem teórica predomina nos instrumentos Prova quando analisado os critérios de avaliação do conteúdo e os aspectos técnicos de organização? Qual a natureza, os elementos e as funções do instrumento Prova na avaliação da aprendizagem em Geografia? Mediante aprimoramento da pesquisa, considera-se que é possível chegar a conclusões enriquecedoras para o campo da avaliação da aprendizagem em Geografia.

\section{REFERÊNCIAS}

BRASIL. Secretaria de Educação Fundamental. Parâmetros curriculares nacionais: história, geografia. Brasília: MEC/SEF, 1997.

Diretrizes Curriculares Nacionais Gerais da Educação Básica. Brasília: MEC, SEB, DICEI, 2013.

Lei 9.394/96, de 20 de dezembro de 1996. Disponível em: http://portal.mec.gov.br/seesp/arquivos/pdf/lei9394_ldbn1.pdf. Acesso em 01 set. 2019.

. Base Nacional Comum Curricular: Educação Infantil e Ensino Fundamental. Brasília: MEC/Secretaria de Educação Básica, 2017.

CAVALCANTI, L.S. Geografia, escola e construção de conhecimento. Campinas: Papirus, 1998.

COLL, César (et all). Psicologia do ensino. Porto Alegre: ArtMed, 2000.

COLL, César; MARCHESI, Álvaro; PALÁCIOS, Jesús e colaboradores. Desenvolvimento psicológico e educação: psicologia da educação escolar, vol. 2. Porto Alegre: ArtMed, 2004.

COLL, César; MARTÍN, Elena; ONRUBIA, Javier. Avaliação da aprendizagem escolar: dimensões psicológicas, pedagógicas e sociais. In: COLL, César et al. Desenvolvimento psicológico e educação. 2. ed. Porto Alegre: Artmed, 2014. p. 370-385.

COSENZA, Ramon M. GUERRA, Leonor B. Neurociência e educação: como o cérebro aprende. Porto Alegre. ArtMed: 2013.

DEPRESBITERIS, Lea. TAVARES, Marialva Rossi. Diversificar é Preciso: instrumentos e técnicas de avaliação de aprendizagem. São Paulo: Senac, 2008. 
FEIJOO, AMLC. A pesquisa e a estatística na psicologia e na educação. Rio de Janeiro: Centro Edelstein de Pesquisas Sociais, 2010, 109p.

FILIZOLA, R. Didática da geografia: proposições metodológicas e conteúdos entrelaçados com a avaliação. Curitiba: Base Editorial, 2009.

GRÉGOIRE, J. Avaliando as aprendizagens: os aportes da psicologia cognitiva. Porto Alegre: Artes Médicas Sul, 2000.

HOFFMANN, Jussara. Avaliação mediadora: uma prática em construção da pré-escola à universidade. 7. Ed. Porto Alegre: Mediação, 1993.

Pontos e Contrapontos: do pensar ao agir em avaliação. 5. ed. Porto Alegre: Mediação, 2000.

Avaliação, mito e desafio: uma perspectiva construtivista. Porto Alegre: Mediação, 2001.

Avaliar para promover: as setas do caminho. 15. ed. Porto Alegre: Editora Mediação, 2014.

KROTON. Manual para elaboração e revisão de questões para avaliação. VP Acadêmica Kroton, 2017.

LENT, Roberto. Cem bilhões de neurônios? Conceitos fundamentais de neurociência. São Paulo: Atheneu, 2010.

LUCKESI, C. C. Avaliação da aprendizagem escolar: estudos e proposições. 22. ed. São Paulo: Cortez, 2011.

Avaliação da aprendizagem escolar. 18 ed. São Paulo: Cortez, 2006.

Editora, 2018.

Avaliação em educação: questões epistemológicas e práticas. São Paulo: Cortez

MORAES, Dirce Aparecida Foletto de. Avaliação formativa: re-significando a prova no cotidiano escolar. 2008. 146f. Dissertação (Mestrado em Educação) - Universidade Estadual de Londrina, Londrina, 2008.

MORETTO, Vasco Pedro. Prova: um momento privilegiado de estudo não um acerto de contas. $2^{\text {a }}$ d. Rio de Janeiro: DP\&A, 2002.

Prova: um momento privilegiado de estudo, não um acerto de contas. 9. ed.

Rio de Janeiro: Lamparina, 2010.

PERRENOUD, Philippe. Avaliação: da excelência à regulação das aprendizagens. Entre duas lógicas. Porto Alegre. ArtMed: 1999. 
RUSSEL, Michael K.; AIRASIAN, Peter W. Avaliação em sala de aula: conceitos e aplicações. Porto Alegre. MacGraw Hill Educacion, Penso. 2015.

SACRISTÁN, Gimeno; GÓMEZ, A. I. Pérez. Compreender e transformar o ensino. Trad. Ernani F. da Fonseca Rosa. 4 ed. Porto Alegre: ArtMed, 1998.

ZABALA, Antoni. A Prática educativa como ensinar. Porto Alegre: Artemed, 1988. 